\title{
Inlay-Clad Gold Alloys
}

\section{THE WIDE RANGE OF PROPERTIES AVAILABLE}

\author{
Robert J. Russell
}

Technical Materials Inc., Lincoln, Rhode Island, U.S.A.

As an economic and reliable alternative to electrodeposited gold, inlay-clad strip offers a number of advantages to the contact designer but the selection of the most suitable gold alloy and basis metal, and the geometry and condition of the finished material, involve a number of complex factors. The properties of gold alloys in inlay form are surveyed to assist the designer in making the most appropriate choice.

Gold inlaid contact bi-metal, in which the gold-or one of its alloys-is located in the form of a continuous stripe along the length of a base metal strip, offers the contact designer an extremely wide range of choice.

The production of these clad inlays involves a twostage pressure bonding operation. First the gold or gold alloy is bonded to a nickel strip which serves as a diffusion barrier between the gold and the basis metal. In the second operation the base metal, usually a copper spring alloy, is first grooved by skiving, the gold/nickel combination is located in this groove, and the composite product is then roll bonded together. A diagram of the complete process is shown in Figure 1.

Long continuous coils of strip result, suitable for high speed pressing or stamping operations to produce connector contacts or semiconductor materials in which the gold or gold alloy is located only where it is needed. A further advantage is the wide range of combinations made possible; many gold alloys are available to provide the most suitable contact properties, the choice of base metal can be made from phosphor-bronze, beryllium-copper, nickel-silver or the more recently developed copper-nickel-tin alloy CA725, while the gold inlay itself can vary from 0.050 inch up to 0.75 inch in width and from as little as 10 microinches in thickness up to one-third of the chosen base metal thickness. Stock can be provided with up to six gold stripes on one or both sides of the base metal.

The condition of the gold or gold alloy is of course that of a wrought product, completely dense, metallurgically bonded to its backing material, and flush with the base metal surface. This last factor ensures that the gold surface is less susceptible to damage in the as-coiled condition and in the subsequent stamping operation, while porosity - a major problem in electrodeposited gold coatings-is reduced to a minimum and occasioned by the presence of dirt particles or scratches when the thickness of the gold inlay is held to a very low figure.

Thus the contact designer is offered an extraordinarily wide range of possibilities, coupled with an economy in his use of gold. Thin layers of gold can be held to within \pm 0.010 inch of the required location, while an alloy of lower gold content than the conventional electroplates can be used. The selection of the optimum alloy depends upon many factors,

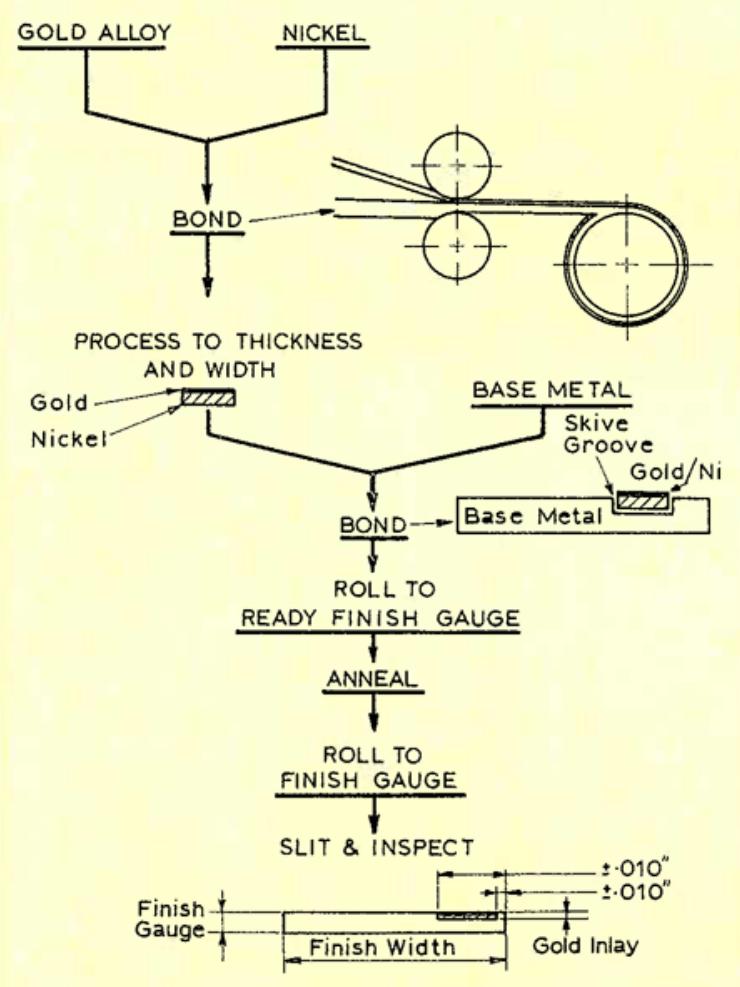

Fig. 1 A flow-sheet showing the process for producing gold clad inlays. Bonding is in two stages; first gold to nickel and then the gold-nickel to the base metal 
including cost, contact pressure, insertion force and wipe, life expectancy and of course the voltage and current involved. The final selection is generally a compromise among all these considerations, but so far there have been too little data available to assist in making a decision. This paper is designed, therefore, to help the designer to make a better selection.

By comparison with electrodeposited golds, the inlay-clad product offers advantages in terms of lower porosity and ease of fabrication, while retaining the virtues of gold in its low contact resistance. These are the properties of major concern to the designer, and an investigation carried out by the writer and reported in more detail in a recent paper (1) provides data on these and other characteristics of a number of gold alloys in inlay-clad form.

\section{Porosity}

Both the nature and the cause of porosity-discontinuities in the gold layer which expose the substrate metal to attack-differ substantially with inlay-clad metals as compared with electrodeposits. In the latter case a tubular-like void in the deposit may arise from a number of factors, including surface imperfections in the metal being plated, the method of electrodeposition, contamination of the electrolyte and of course the presence of dirt and scratches in the substrate. On the other hand, the clad gold is produced as a solid layer free from discontinuities. Only by reason of physical damage occurring during manufacture or subsequent fabrication of a component, or of the presence of contaminating particles, and provided only that a reasonable thickness of gold has been applied, can porosity arise in the gold inlay. And sophisticated methods of production in clean operating areas serve still further to reduce the hazard of porosity.

In the investigation of porosity, gold and a number of its alloys were studied in the form of inlays in a range of thicknesses, $10,20,30,40,50,75$ and 100 microinches, in the copper-nickel-tin alloy CA725 with, in all cases, a nickel interlayer.

The method used for porosity testing was the twohour nitric acid vapour test laid down in Western Electric Specification "Porosity of Metallic Coatings on Copper, Copper-base Alloys and Nickel".. After two days exposure and thermal treatment, the specimens were viewed at $10 \times$, and the number of corrosion products (pores) per square centimetre was assessed.

The total number of pores naturally fell off with increasing thickness of gold above 20 microinches (below this thickness the porosity counts went up into the hundreds). The results obtained showed that there was no major difference between the alloys investigated, but they did establish that, while a

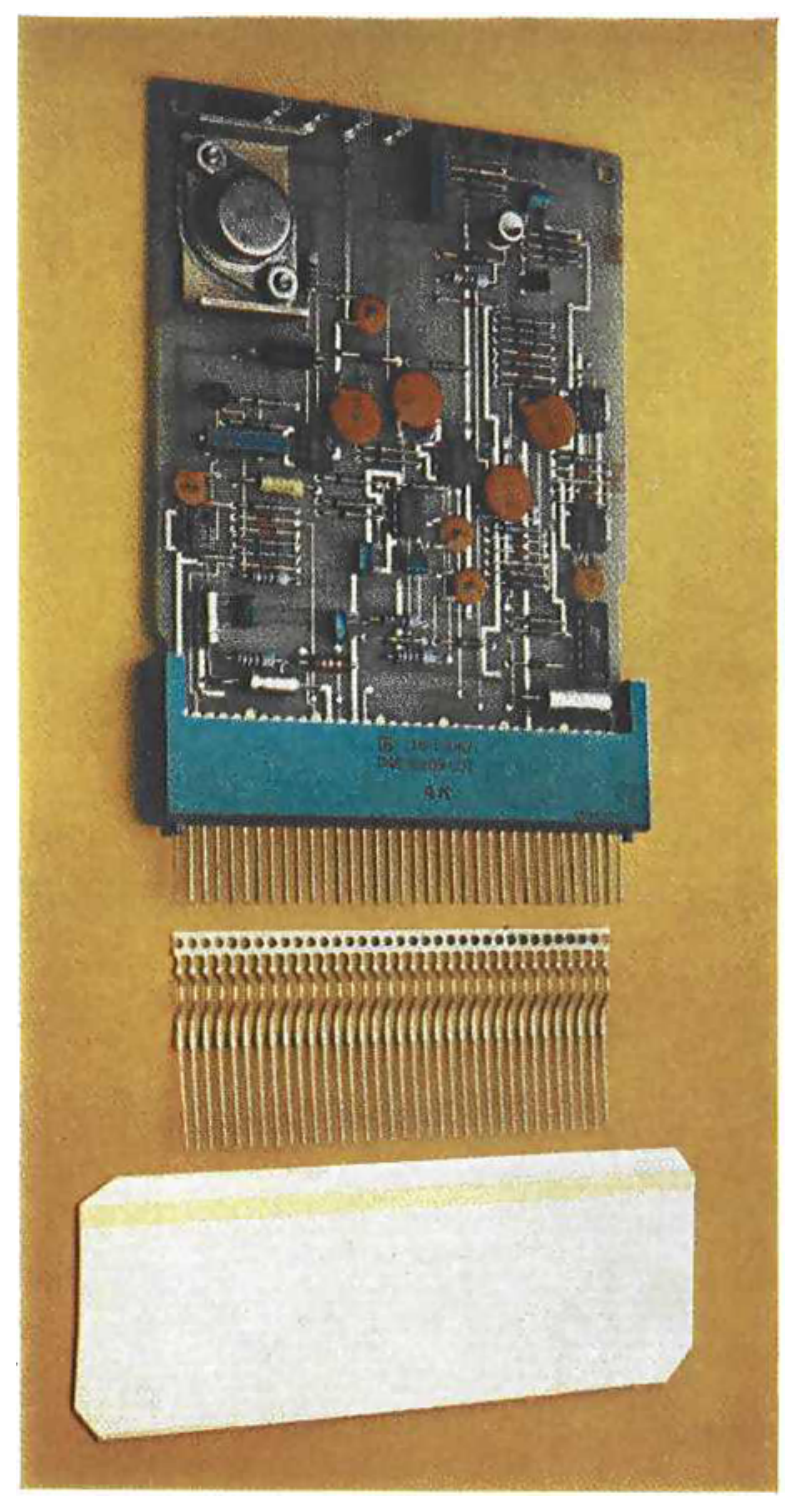

Fig. 2 A Winchester/Honeywell printed cireuit edgeboart connector, showing the sequence from the gold clad inlay below to the press part and to final assembly. The inlay is a 75 per cent gold alloy 0.00010 inch in thickness

thickness of 100 microinches is required to achieve virtual freedom from porosity in electrodeposited gold coatings, below this thickness porosity in plated golds increases at a greater rate than porosity in clad golds. Figure 4 shows the range of porosity counts for the clad gold alloys by comparison with results obtained by other workers for electroplated golds.

\section{Ease of Fabrication}

The possible routes to economy in localising the use of gold in the design of a contact are:

Selective electroplating prior to fabrication.

Selective inlay cladding prior to fabrication.

Selective location of gold after fabrication by either plating or welding. 


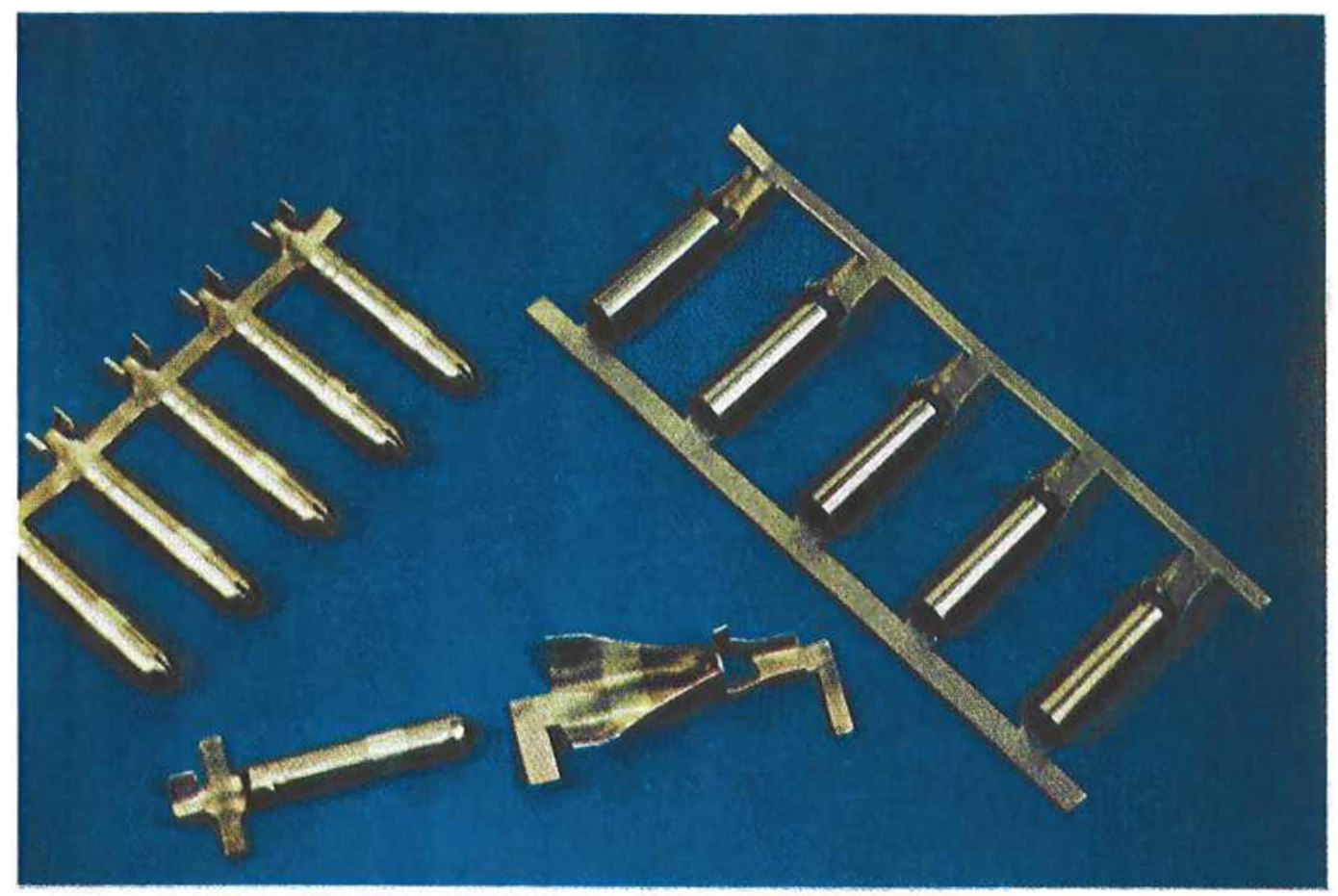

Fig. 3 Connectors for truck anti-brake locking circuitry require gold contacts for resistance to oxidation and corrosion. These components, produced from gold inlay-clad copper-nickel-tin alloy, showed a substantial saving by comparison with the earlier method of production from gold-plated phosphor-bronze

In the two former cases the designer must have assurance that the gold contact surface will remain unimpaired and will not fracture or come away from its substrate during the forming operations. In other words, the gold layer must withstand forming.

The standard test for the formability of plated products described in ASTM Specification B489-68, "Bend Test for Ductibility of Plated Metals", is to bend a narrow strip through $180^{\circ}$ over mandrels of various diameters, the level of acceptability occurring at the diameter when no cracks are visible at $10 \times$ magnification. With diameters under 0.064 inch this procedure becomes difficult as the mandrels are too fragile, and a special fixture, designed by AMP Inc., was used to obtain radii down to 0.003 inch.

Inlay clad samples of gold and of six gold alloys were prepared by rolling with three different reductions-10, 30 and 60 per cent-to a finished thickness of $0.0125 \mathrm{inch}$. (These reductions correspond approximately to quarter-hard, three-quarter hard and spring tempers.) The gold thickness on all samples was 50 microinches, and the base metal was again CA725; in addition samples of electroplated soft gold on nickel were prepared and given a 10 per cent reduction by rolling. All bends were made transverse to the direction of rolling, with the gold on the convex side.

Naturally the degree of formability was greater with the lower reductions in rolling. The 10 per cent reduction samples would generally withstand bending over radii as small as 0.008 to 0.010 inch, the 30 per cent reduced samples withstood 0.016 to 0.020 inch radii, while the spring temper specimens failed

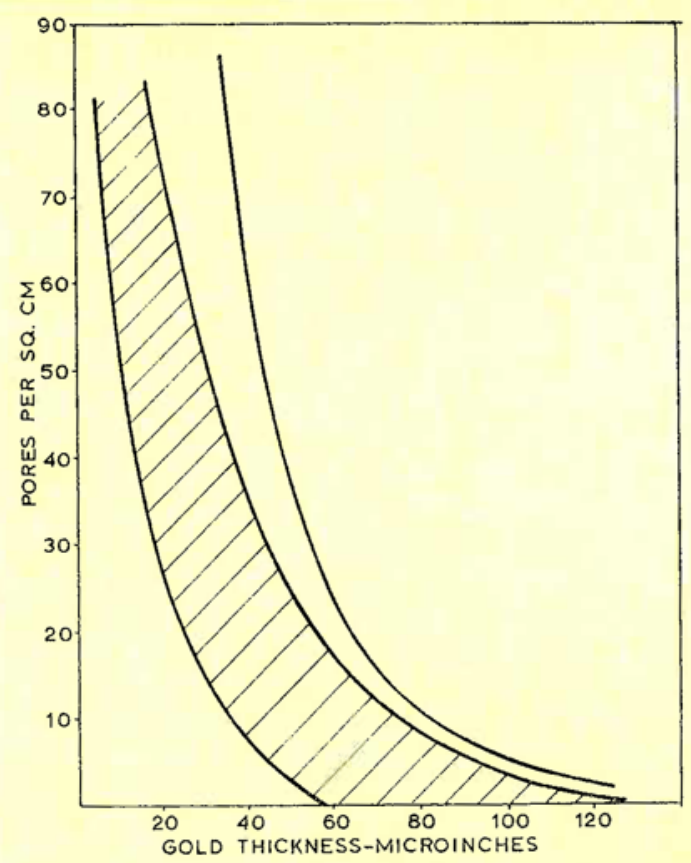

Fig. 4 The range of porosity counts-corrosion products from the nitric acid vapour test-as a function of gold thickness. The cross-hatched band shows the range of points for a number of gold alloys in inlay-clad form. The single curve shows average values for electrodeposited gold 
between 0.020 and 0.030 inch radii. The performance of the electroplated gold, even at a radius of 0.125 inch, was relatively poor, and all samples failed at smaller radii. In this connection it may be mentioned that some specifications forbid the forming of parts after electroplating with hard gold.

\section{Hardness and Wear}

A further advantage of the clad metal inlay technique is the possibility of selecting from a wide range of gold alloys, many of which would be impossible to electrodeposit.

Knoop hardness values obtained by various percentage reductions in rolling are shown in Figure 5 for gold itself and for fourteen gold alloys. Naturally the hardness of an alloy in inlay form is influenced by the rolled temper specified for the basis metal.

Wear testing on pure gold and the fourteen alloys in inlay clad form was carried out in a fixture giving reciprocating movement with a half-inch stroke against a rounded 75 per cent gold alloy rod having a 0.0625 inch radius and loaded

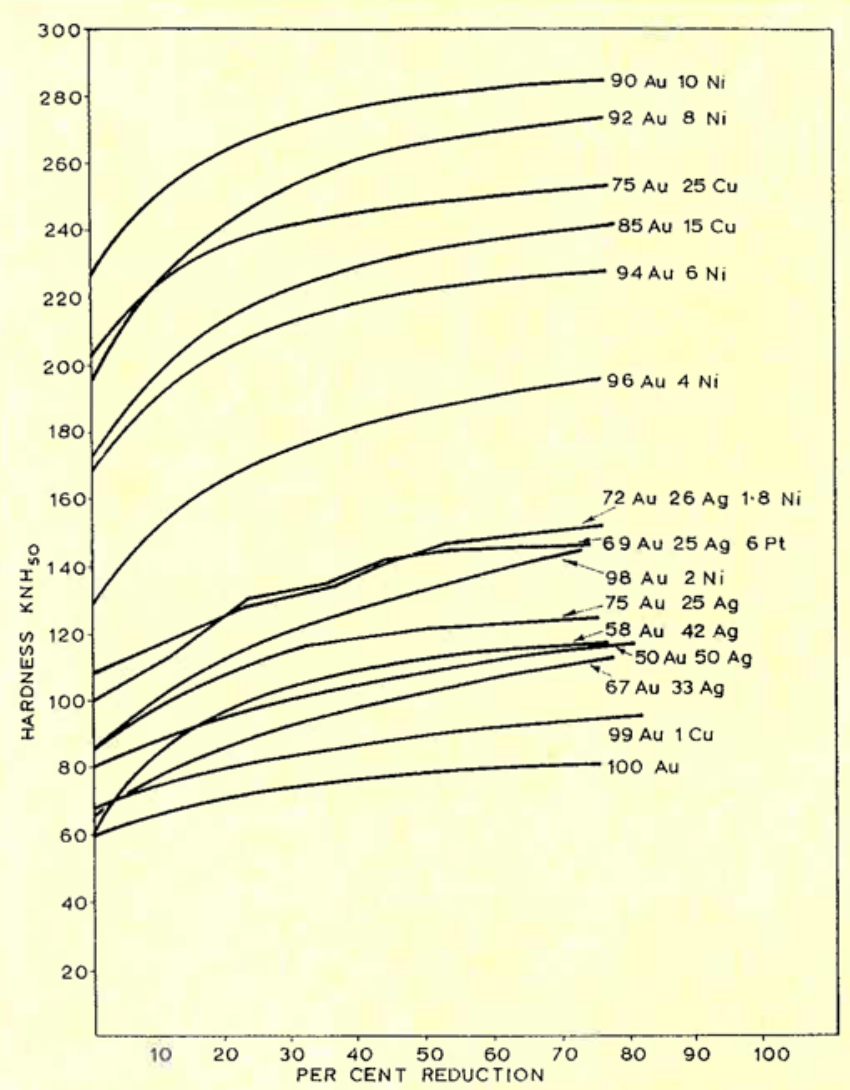

Fig. 5 Knoop hardness values after various reductions

Table 1

\section{Wear Test Data for Gold Alloys}

\begin{tabular}{|c|c|c|c|c|c|c|c|c|}
\hline \multicolumn{3}{|c|}{ Gold Properties } & \multicolumn{6}{|c|}{ Complete Strokes } \\
\hline \multirow{2}{*}{ Alloy } & \multirow{2}{*}{\begin{tabular}{c|} 
Thickness \\
Microinches
\end{tabular}} & \multirow{2}{*}{$\mathrm{KNH}_{50}$} & 2 & 4 & 6 & 8 & 10 & 100 \\
\hline & & & \multicolumn{6}{|c|}{ Number of Wear-Through Points in Wear Track } \\
\hline $75 \mathrm{Au}-25 \mathrm{Cu}$ & 156 & 248 & 0 & 0 & 0 & 0 & 0 & 0 \\
\hline $90 \mathrm{Au}-10 \mathrm{Ni}$ & 105 & 281 & 0 & 0 & 0 & 0 & 0 & 一 \\
\hline $92 \mathrm{Au}-8 \mathrm{Ni}$ & 74 & 268 & 0 & 0 & 0 & 0 & 0 & 4 \\
\hline $99 \mathrm{Au}-1 \mathrm{Co}$ & 102 & 86 & 0 & 0 & 2 & 2 & 3 & - \\
\hline $85 \mathrm{Au}-15 \mathrm{Cu}$ & 69 & 168 & 0 & 0 & 1 & 8 & 6 & 10 \\
\hline $94 \mathrm{Au}-6 \mathrm{Ni}$ & 90 & 222 & 2 & 1 & 1 & 3 & 1 & - \\
\hline $96 \mathrm{Au}-4 \mathrm{Ni}$ & 87 & 186 & 0 & 2 & 2 & 6 & 15 & - \\
\hline 100Au & 92 & 80 & 3 & 2 & 4 & 8 & 5 & - \\
\hline $98 \mathrm{Au}-2 \mathrm{Ni}$ & 83 & 142 & 2 & 12 & 55 & 75 & 105 & - \\
\hline $69 \mathrm{Au}-25 \mathrm{Ag}-6 \mathrm{Pt}$ & 92 & 143 & 2 & 15 & 34 & 65 & $40 \%$ & - \\
\hline $75 \mathrm{Au}-25 \mathrm{Ag}$ & 78 & 122 & 9 & 33 & 70 & 150 & $90 \%$ & 一 \\
\hline $58 \mathrm{Au}-42 \mathrm{Ag}$ & 100 & 115 & 2 & 3 & $60 \%$ & $75 \%$ & $95 \%$ & - \\
\hline $72 \mathrm{Au}-26.2 \mathrm{Ag}-1.8 \mathrm{Ni}$ & 99 & 145 & 4 & 24 & $60 \%$ & $75 \%$ & $95 \%$ & - \\
\hline $67 \mathrm{Au}-33 \mathrm{Ag}$ & 108 & 104 & 48 & 80 & $50 \%$ & $75 \%$ & $90 \%$ & - \\
\hline
\end{tabular}

The figures below the double lines denote the percentage of wear track covered by corrosion products when wear-through was extensive 
Table II

Contact Resistance after Exposure at $100^{\circ} \mathrm{C}-$ Milliohms

\begin{tabular}{|c|c|c|c|c|c|c|c|c|}
\hline \multirow[t]{2}{*}{ Alloys } & \multicolumn{8}{|c|}{ Hours } \\
\hline & 0 & 16 & 42 & 90 & $\begin{array}{c}90 \\
\text { Slide }\end{array}$ & $\begin{array}{c}1000 \\
\text { Average }\end{array}$ & $\begin{array}{c}1000 \\
\text { Median }\end{array}$ & $\begin{array}{c}1000 \\
\text { Range }\end{array}$ \\
\hline $100 \mathrm{Au}$ & 0.96 & 0.97 & 1.05 & 1.18 & 0.52 & 1.16 & 1.15 & $1.03-1.30$ \\
\hline $75 \mathrm{Au}-25 \mathrm{Cu}$ & 2.00 & na & 3.40 & 8.02 & 1.15 & 6.70 & 3.50 & $1.60-32.00$ \\
\hline $85 \mathrm{Au}-15 \mathrm{Cu}$ & 1.46 & 1.71 & 2.50 & 2.95 & 1.02 & 25.80 & 31.00 & $1.50-58.00$ \\
\hline $69 \mathrm{Au}-25 \mathrm{Ag}-6 \mathrm{Pt}$ & 0.98 & 1.09 & 1.33 & 1.16 & 0.75 & 5.70 & 5.30 & $4.50-7.10$ \\
\hline $72 \mathrm{Au}-26.2 \mathrm{Ag}-1.8 \mathrm{Ni}$ & 1.20 & 0.97 & 1.11 & 1.22 & 0.72 & 2.20 & 1.90 & $1.40-30.00$ \\
\hline $99 \mathrm{Au}-1 \mathrm{Co}$ & 1.18 & 1.09 & 1.41 & 1.14 & 0.78 & 1.19 & 1.17 & $1.07-1.38$ \\
\hline $50 \mathrm{Au}-50 \mathrm{Ag}$ & 1.17 & 1.34 & 1.50 & 1.65 & 1.20 & 8.40 & 8.00 & $1.55-16.00$ \\
\hline $58 \mathrm{Au}-42 \mathrm{Ag}$ & 1.31 & 1.13 & 1.87 & 1.65 & 1.02 & 29.68 & 3.30 & $1.40-130.0$ \\
\hline $67 \mathrm{Au}-33 \mathrm{Ag}$ & 1.10 & 1.20 & 1.42 & 1.14 & 1.05 & 40.35 & 30.00 & $5.50-100.0$ \\
\hline $75 \mathrm{Au}-25 \mathrm{Ag}$ & 1.13 & 1.01 & 1.20 & 1.24 & 0.75 & 4.60 & 3.00 & $1.00-13.50$ \\
\hline $90 \mathrm{Au}-10 \mathrm{Ni}$ & 1.34 & 1.74 & 2.12 & 1.93 & 1.04 & 2.46 & 2.48 & $2.10-2.60$ \\
\hline $92 \mathrm{Au}-8 \mathrm{Ni}$ & 1.23 & 2.18 & 1.62 & 2.29 & 1.10 & 2.44 & 2.55 & $1.75-3.05$ \\
\hline $94 \mathrm{Au}-6 \mathrm{Ni}$ & 1.28 & 1.25 & 1.67 & 2.12 & 0.92 & 1.95 & 1.90 & $1.75-2.15$ \\
\hline $96 \mathrm{Au}-4 \mathrm{Ni}$ & 1.13 & 1.17 & 1.23 & 1.19 & 1.00 & 1.96 & 1.85 & $1.65-2.32$ \\
\hline $98 \mathrm{Au}-2 \mathrm{Ni}$ & 0.94 & 1.02 & 0.96 & 1.19 & 0.88 & 2.12 & 2.10 & $1.95-2.30$ \\
\hline
\end{tabular}

to 100 grams. Wear testing without lubrication was not proceeded with beyond 100 strokes, as galling and prow formation were observed after only a few strokes, and the samples were evaluated for wear through the gold layer by exposure for two hours to nitric acid vapour and counting the number of corrosion products on the half-inch wear track or, when wear was extensive, by assessing the percentage of wear track covered by corrosion products. The results, set out in Table I, show of course that resistance to wear generally increases with hardness of the alloy. With lubrication, there was minimum wear when testing was stopped at 16,000 strokes.

\section{Contact Resistance}

To evaluate the contact resistance to be expected of these alloys, flat specimens of each, with approximately 100 microinches of gold inlay, were thoroughly cleaned and mated with a pure gold probe turned to a 0.0625 inch radius. The contact load was 100 grams, and up to 20 readings were taken with a milliohmmeter.

Determinations were made first on the as-cleaned samples, and then after periods of $16,42,90$ and 1000 hours in a circulating air furnace at $100^{\circ} \mathrm{C}$. After 90 hours it was found that by sliding the sample slightly under the probe, to disrupt any film formed, contact resistance values fell as would be expected.

The 1000 hour exposure data produced a wide spread, and average, median and range values are therefore reported. Those alloys containing copper and silver showed very mottled surfaces where corrosive attack was not uniform, but the alloys employing nickel and cobalt gave, as will be seen from Table II, much more uniform results.

\section{Conclusion}

Inlay-clad gold and gold alloys are now a prominent feature in the design of electronic and electrical connections as an economic and reliable alternative to the use of electrodeposited gold. They permit a wide variety of new material combinations; not only are many gold alloys available, but thicknesses and widths of inlay offer a wide range of possibilities, while any conventional base metal alloy can be used as the substrate. The final selection of the most suitable combination usually benefits from consultation between the designer and the manufacturer of inlay-clad materials.

\section{Reference}

I R. J. Russell "Properties of Inlay Clad Wrought Gold Alloys" Seventh Annual Connector Symposium, October 1974: also Fifth Plating in the Electronics Industry Symposizm, American Electroplaters' Society, March 1975 